\title{
Strategi Pengembangan Potensi Wisata Alam di Desa Abangsongan, Kintamani, Kabupaten Bangli, Bali
}

\author{
Tyas Raharjeng Pamularsih \\ Politeknik Negeri Bali \\ *Email: ajeng13@pnb.ac.id
}

\begin{abstract}
The Kintamani area is very famous for natural tourist destinations such as Lake Batur and Mount Batur. However, it turns out that Kintamani has several other natural tourism potentials that are not yet known by tourists, such as Mount Abang in Abangsongan Village. This village has potential in the tourism sector which is very potential, including the lake which is used as water tourism, forest tourism, Mount Abang which has not been optimally developed. The purpose of this research is to identify the tourism potential in Abangsongan Village and find out a suitable development strategy using the SWOT analysis technique. The data used by the author is in the form of qualitative data collected through direct observation and interviews. The data obtained in the field will be analyzed using qualitative descriptive analysis techniques by describing the situation in the field. In addition, there is also a need for a study of the potential and appropriate policies in realizing Abangsongan Village into a tourist destination. Based on the results of the SWOT analysis, the tourism development strategy in Abangsongan Village that may be implemented is as follows: Promotion and publication through the creation of tour packages, construction of trekking routes and outbound facilities, training and counseling on environmental conservation, coordination of protection of tourist areas, periodic evaluation and monitoring of impacts tourism, Collaboration and cooperation with investors regarding the development and management of existing natural tourism potential, Empowerment of communities around tourist areas in Abangsongan Village especially around Lake Batur and Mount Abang, Making management plans and stabilizing tourism areas in Abangsongan Village, Training in tourism such astraining guiding tour, homestay management andtraining culinary.
\end{abstract}

Keywords: Tourism Potential, Development, Strategy, SWOT.

\begin{abstract}
Abstrak
Kawasan Kintamani sangat terkenal dengan destinasi wisata alam seperti Danau Batur dan Gunung Batur. Namun, ternyata di Kintamani memiliki beberapa potensi wisata alam lainnya yang belum diketahui wisatawan seperti Gunung Abang yang ada di Desa Abangsongan. Desa ini memiliki potensi dalam bidang pariwisata yang sangat potensial di antaranya danau yang digunakan sebagai wisata air, hutan wisata, Gunung Abang yang belum secara optimal dikembangkan. Tujuan dari penelitian ini adalah untuk mengidentifikasi potensi wisata yang ada di Desa Abangsongan dan mengetahui strategi pengembangan yang cocok dengan menggunakan teknik analisis SWOT. Data yang digunakan oleh penulis berupa data kualitatif yang dikumpulkan melalui observasi langsung dan wawancara. Data yang didapat di lapangan akan dianalisis menggunakan teknik analisis deskriptif kualitatif dengan menggambarkan situasi yang ada di lapangan. Selain itu, juga perlu adanya kajian mengenai potensi dan kebijakan yang sesuai dalam merealisasikan Desa Abangsongan menjadi suatu destinasi wisata. Berdasarkan hasil analisis SWOT maka strategi pengembangan wisata Desa Abangsongan yamg mungkin dapat diterapkan sebagai berikut : Promosi dan publikasi melalui pembuatan paket wisata, Pembangunan jalur trekking dan sarana outbond, Pelatihan dan penyuluhan konservasi lingkungan, Koordinasi perlindungan kawasan wisata, Evaluasi dan monitoring secara berkala mengenai dampak pariwisata, Kolaborasi dan kerja sama dengan investor mengenai pengembangan dan pengelolaan potensi wisata alam yang ada, Pemberdayaan masyarakat sekitar kawasan wisata di Desa Abangsongan khusunya sekitar Danau Batur dan Gunung Abang, Pembuatan rencana pengelolaan dan pemantapan kawasan wisata di Desa Abangsongan, Pelatihan dalam bidang kepariwisataan seperti pelatihan tour guiding, pengelolaan homestay dan pelatihan culinary.
\end{abstract}

Kata Kunci: Potensi Wisata, Pengembangan, Strategi, SWOT . 


\section{Pendahuluan}

Pariwisata merupakan salah satu sektor paling terkenal dan mendatangkan banyak profit di Indonesia. Pariwisata Indonesia sudah dikenal tidak hanya secara nasional saja melainkan juga sampai mata internasional. Indonesia memiliki banyak sekali jenis wisata yang menarik untuk dikunjungi dan dinikmati mulai dari wisata alam, sejarah hingga wisata budaya. Seperti pendapat dari Ismayanti (2010) yang mengelompokkan pariwisata menjadi berbagai jenis berdasarkan jenis wisatanya seperti wisata kuliner, wisata budaya, wisata sejarah dan masih banyak lainnya. Pariwisata juga memberikan dampak positif terhadap masyarakat lokal di sekitar destinasi wisata dan pemerintah terutama dalam membuka lapangan kerja dan peningkatan kesejahteraan dan perekonomian. Indonesia sebagai negera berkembang dalam pembangunan berusaha untuk membangun industri pariwisata sebagai salah satu usaha untuk mencapai neraca perdagangan luar negeri yang berimbang dan diharapkan juga bisa menjadi pemasukan devisa dapat bertambah serta meningkatkan perekonomian masyarakatnya (Pendit, 2002).

Salah satu kawasan di Indonesia yang banyak dikunjungi wisatawan adalah Pulau Bali. Pulau Bali memiliki banyak sekali daya tarik wisata yang menarik mulai dari wisata alam, sejarah, budaya hingga adat istiadat. Salah satu wilayah di Bali yang banyak dikunjungi adalah Kintamani yang terletak di Kabupaten Bangli. Kawasan Kintamani sangat terkenal dengan destinasi wisatanya yaitu Danau Batur dan Gunung Batur. Selain itu, ternyata di Kintamani memiliki beberapa potensi wisata lainnya yang dapat dikembangkan terutama di Desa Abangsongan. Desa ini memiliki potensi dalam bidang pariwisata di antaranya danau yang digunakan sebagai wisata air, hutan wisata, gunung dan situs purbakala. Namun, potensi wisata tersebut belum secara optimal dikembangkan sehingga belum banyak wisatawan yang mengetahuinya. Penelitian ini memiliki tujuan untuk mengidentifikasi potensi- potensi wisata yang ada di Desa Abangsongan yang belum optimal sehingga bisa dicarikan strategi pengembangan yang sesuai sehingga nantinya mampu untuk menjadi sumber penghasilan dan pendapatan bagi masyarakat disana. Daya tarik wisata merupakan istilah lain dari obyek wisata yang lebih familiar di telinga orang awam. Daya tarik itu sendiri menurut para ahli memiliki beberapa definisi. Salah satu definisi daya tarik wisata menurut Undang-Undang Republik Indonesia No 10. Tahun 2009 didefinisikan sebagai suatu hal yang memiliki keunikan, kemudahan dan nilai yang bisa berupa keanekaragaman hayati, budaya dan buatan manusia yang menjadi tujuan kunjungan wisata (Hermawan, 2017). Menurut Yoeti (2008) daya tarik wisata adalah atraksi wisata yang dapat berupa apapun itu yang dapat ditawarkan kepada wisatawan yang ingin berkunjung ke suatu negara atau daerah tujuan wisata (DTW) tertentu. Daya tarik wisata terdiri dari beberapa jenis, di antaranya atraksi wisata alam, budaya, sosial dan buatan. Sebuah daya tarik wisata memerlukan strategi pengembangan di dalamnya guna menunjang kegiatan pariwisata di dalamnya. Menurut Cooper (1998) bahwa daya tarik wisata haruslah memiliki unsur 4A di dalamnya yang meliputi atraksi, amenitas, aksesibiltas, dan ancilliary atau pelayanan tambahan yang merupakan komponen utama dalam sebuah daya tarik wisata.

Penelitian ini melihat adanya peluang besar apabila potensi-potensi wisata yang ada di Desa Abangsongan mampu dikembangkan secara optimal. Namun, untuk mewujudkan semua itu maka diperlukan adanya perencanaan, pengorganisasian, pengarahan, dan pengawasan. Hal tersebut merupakan satu kesatuan yang saling berhubungan satu dengan lainnya. Selain itu, pengembangan pariwisata berkelanjutan ini dapat dilakukan berdasarkan beberapa prinsip seperti partisipasi pemangku kepentingan, masyarakat di sekitar potensi wisata, mempertahankan pemanfaatan sumber daya yang ada, menyediakan tujuan komunitas, memperhatikan segala sumber pendukung, mengendalikan dan mengevaluasi seperti akuntabilitas, pelatihan dan promosi (Mahfud, Mulyani, Indartono, \& Setyawati, 2018).

Dalam melakukan pengembangan potensi wisata di suatu tempat diperlukan strategi pengembangan yang tepat sesuai dengan potensi wisata yang ada dan kebutuhan agar mampu 
mendapatkan hasil yang maksimal. Sementara itu, menurut Pearce (1981:12) pengembangan pariwisata dapat didefinisikan sebagai suatu usaha untuk melengkapi atau meningkatkan fasilitas dan pelayanan yang dibutuhkan masyarakat.

Berkaitan dengan kegiatan pengembangan potensi pariwisata juga diperlukan adanya strategi di dalamnya untuk mencapai suatu hasil optimal yang diinginkan. Strategi didefinisikan sebagai pola tujuan, kebijakan program atau alokasi sumber daya yang dapat menentukan apakah sebuah organisasi melakukan itu. Dengan demikian strategi merupakan perpanjangan dari misi membentuk jembatan antara organisasi dengan lingkungannya (Bryson, 1999). Berdasarkan definisi di atas maka yang dimaksud dengan strategi pengembangan adalah upayaupaya yang dilakukan dengan tujuan memajukan, memperbaiki dan meningkatkan kondisi kepariwisataan suatu obyek dan daya tarik wisata sehingga mampu menjadi mapan dan ramai untuk dikunjungi oleh wisatawan serta mampu memberikan suatu manfaat baik bagi masyarakat sekitar lokasi wisata dan lebih lanjut menjadi pemasukan bagi pemerintah.

\section{Metode Penelitian}

Metode penelitian yang digunakan adalah deskriptif kualitatif dimana permasalahan yang dibahas dalam penelitian ini bersifat sementara dan akan berubah serta berkembang saat penulis terjun ke lapangan. Selain itu, metode penelitian ini tidak berkaitan dan berhubungan dengan angka melainkan penulis mendeskripsikan, menguraikan dan menggambarkan data yang didapat selama ada di lapangan. Metode ini dapat diartikan sebagai prosedur pemecahan masalah yang diteliti dengan menggambarkan keadaan subyek atau obyek penelitian pada saat sekarang berdasarkan pada fakta yang nampak dan apa adanya Soejono \& Abdurrahman, 1999) Data yang digunakan dalam penelitian deskriptif kualitatif adalah data primer dan data sekunder. Data primer diperoleh langsung dari lokasi penelitian secara lengkap serta berhubungan dengan masalah yang diteliti (Bungin, 2008). Pengambilan data dilakukan melalui wanacara tidak terstruktur dimana wawancara ini bersifat bebas dan tidak menggunakan pedoman wawancara yang sistematis dan lengkap serta untuk pengumpulan data juga digunakan teknik observasi langsung serta dokumentasi (Itamar, 2016). Informan yang dipilih meliputi pemuka Desa Abangsongan, pelaku usaha wisata di lokasi, serta masyarakat lokal di sana.

Data sekunder merupakan data pendukung dari data primer yang diperoleh dari hasil studi literature, buku, jurnal serta website untuk menambah data mengenai pengembangan pariwisata alam, manajemen strategu serta informasi yang berhubungan dengan potensi wisata yang ada di Desa Abangsongan. Analisis data yang digunakan dalam penelitian ini adalah analisis deskriptif kualitatif dan analisis SWOT. Untuk mengidentifikasi strategi pengembangan potensi wisata alam disana menggunakan analisis SWOT. Proses analisis dimulai dengan mengetahui visi dari Desa Abangsongan terlebih dahulu. Visi yang berhubungan khusus aktivitas pariwisata di sana belum ada namun untuk visi dari Desa Abangsongan sendiri adalah " terwujudnya masyarakat Desa Abangsongan yang SANTI ( sejahtera, aman, nyaman, tertib, dan indah ) dengan tetap mensejajarkan kemampuan diri dengan lingkungan sekitarnya bersama masyarakat Desa Abangsongan yang berlandaskan Tri Hita Karana". Visi ini nantinya akan menjadi dasar analisis SWOT. Analisis ini digunakan untuk mengidentifikasi kekuatan, kelemahan, peluang dan ancaman terhadap potensi wisata alam di Desa Abangsongan. Setelah proses identifikasi potensi wisata berdasarkan SWOt maka langkah selanjutnya adalah membuat matrik SWOT yang memungkinkan untuk menghasilkan 4 strategi alternative untuk pengembangan potensi wisata alam tersebut.

Untuk menyusun strategi yang relevan dalam pengembangan wisata alam di Desa Abangsongan perlu dilakukan analisis SWOT . Selain itu, daya dukung dan tampung yang ada di Desa Abangsongan masih belum mengalami over carrying capacity dan belum menjadikan daya tarik wisata di sana menjadi mass tourism. Hal ini berarti bahwa daya dukung kawasan wisata di Desa Abangsongan masih merupakan peluang untuk dapat dikembangkan dan 
dipertahankan agar tetap berada pada kisaran tersebut. Pengembangan industri pariwisata diharapkan juga mampu menunjang upaya pelestarian alam, kekayaan hayati dan kekayaan budaya. Pengembangan kawasan wisata merupakan alternatif yang diharapkan mampu mendorong baik itu potensi ekonomi maupun upaya-upaya pelestarian lingkungan. Pengembangan daya tarik wisata alam juga harus memperhatikan beberapa aspek seperti perencanaan pembangunan daya tarik wisata alam, kelembagaan, sarana dan prasarana, pengelolaan, pengusahaan kesempatan, pemasaran dan penelitian pengembangan.

Formulasi strategis memiliki tujuan untuk menyusun strategi yang relevan dengan visi misi organisasi dan DTW. Formulasi strategi harus dilakukan agar mampu menyelesaikan masalah yang ada saat ini maupun yang akan terjadi pada masa mendatang. Analisis ini berdasarkan logika yang dapat memaksimalkan kekuatan dan peluang namun secara bersamaan juga dapat meminimalkan kelemahan dan ancaman. Analisis SWOT dapat menggambarkan secara jelas mengenai peluang dan ancaman eksternal yang dihadapi sehingga dapat disesuaikan dengan kekuatan dan kelemahan yang dimilikinya. Matriks ini dapat menghasilkan empat kemungkinan alternatif strategi yaitu Strategi StrengthOpportunities (Strategi S-O), Strategi StrengthThreats (Strategi S-W), Strategi WeaknessOpportunities (Strategi W-O), dan Strategi WeaknessThreats (Strategi W-T).

\section{Hasil dan Pembahasan}

\subsection{Potensi Wisata Desa Abangsongan}

Desa Abangsongan termasuk dalam wilayah adminstratif Kecamatan Kintamani Kabupaten Bangli yang terbagi dalam 6 dusun (banjar) yaitu, Dusun Abang, Belong Dauhan, Belong Danginan, Abangsongan, Bias Kaja, dan Bias Kelod. Desa Abangsongan sendiri terletak di ketinggian 850 meter di atas permukaan laut yang dibatasi oleh Desa Cemara Lindung di sebelah utara, sedangkan di sebelah selatan berbatasan dengan Desa Penaga Landih, sebelah timur berbatasan dengan Tukad Unda, dan sebelah barat berbatasan dengan Tukad Melanget.

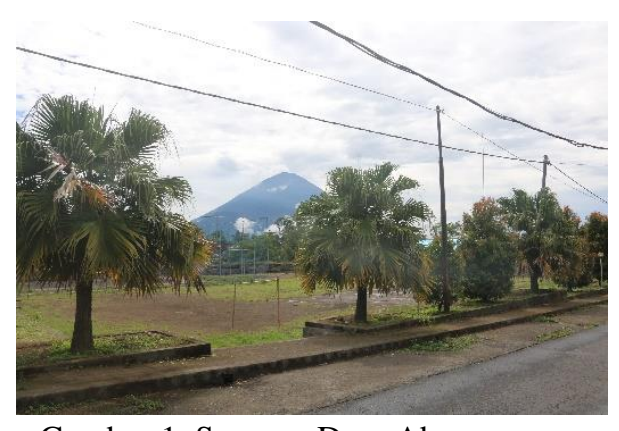

Gambar 1. Suasana Desa Abangsongan

Sebenarnya pada tahun 2018 sendiri Desa Abangsongan telah ditetapkan menjadi desa wisata berdasarkan Peraturan Bupati (Perbup) Bangli Nomor 4 Tahun 2018 tentang Perbuahan Ketiga atas Perbup Bangli Nomor 16 Tahun 2014 tentang Desa Wisata. Dalam hal ini, Desa Abangsongan ditetapkan menjadi desa wisata dengan potensi wisata dalam bidang wisata alam. Walaupun sudah ditetapkan menjadi salah satu desa wisata di Bangli namun masih ada banyak potensi wisata terutama wisata alam di Desa Abangsongan yang belum dikembangkan dan dikelola secara optimal seperti pengelolaan. Danau Batur dan Gunung Abang. Potensi-potensi seperti kawasan hutan wisata, danau serta gunung tersebut dapat dikembangkan menjadi salah satu daya tarik wisata di Desa Abangsongan untuk membantu tingkat pendapatan dan kesejahteraan masyarakat lokal. Desa Abangsongan yang terletak di Kecamatan Kintamani memiliki beberapa potensi wisata namun belum optimal dalam hal pengembangan dan pengelolaannya seperti Danau Batur yang digunakan sebagai wisata air, hutan wisata, Gunung Abang, kegiatan budaya dan situs purbakala. 
Potensi wisata pertama yang bisa dikembangkan oleh masyarakat di Desa Abangsongan adalah Gunung Abang. Gunung ini terletak satu lokasi dengan Gunung Batur dan posisinya sendiri berhadap-hadapan. Gunung Abang terletak di sebelah timur sedangkan Gunung Batur terletak di sebelah barat. Gunung ini memiliki ketinggian 2152 di atas permukaan laut dan merupakan puncak tertinggi ketiga di Pulau Bali. Selain itu, gunung ini juga merupakan titik tertinggi dari pematang kaldera yang mengelilingi Gunung Batur yang memiliki luas 13,8x 10 $\mathrm{km}$.

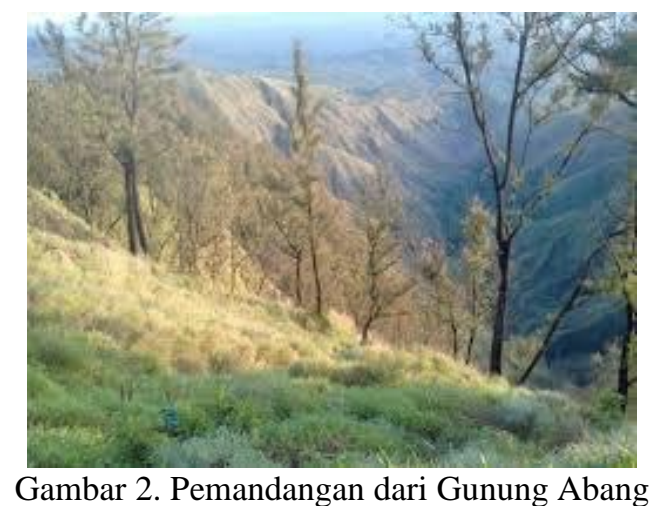

Gunung Abang banyak dikunjungi oleh wisatawan yang memang menyukai olahraga mendaki gunung dan trekking. Gunung Abang ini menyuguhkan pemandangan yang sangat indah dengan pemandangan pohon, bukit hijau serta jalur trekking menuju ke puncak Gunung Abang dihiasi dengan banyak tumbuhan, semak belukar, pohon tumbang serta jalur trekking yang cukup curam dan licin apabila musim hujan mulai turun. Walaupun banyak pendaki yang datang berkunjung namun ternyata Gunung Abang ini sebenarnya belum banyak diketahui dan dikunjungi turis. Ini dikarenakan kurangnya sarana promosi serta masih terbatasnya sarana dan prasarana pendukung di Gunung Abang ini.

Potensi wisata selanjutnya adalah Danau Batur. Seperti kita sudah ketahui bahwa Danau Batur adalah salah daya tarik wisata alam yang ada di Pulau Bali. Danau ini terletak di lereng Gunung Batur di atas ketinggian 1.050 meter dan memiliki luas $16 \mathrm{~km}^{2}$.Danau Batur ini termasuk dalam beberapa wilayah desa administratif di Kecamatan Kintamani salah satunya adalah Desa Abangsongan.

Danau Batur ini merupakan salah satu danau kaldera aktif yang memiliki keindahan panorama yang disebabkan karena airnya yang bisa berubah warna. Ini disebabkan karena adanya kandungan belerang. Selain sebagai daya tarik wisata ternyata Danau Batur juga digunakan oleh masyarakat lokal sebagai lokasi karamba ikan air tawar. Namun, pengelolaan dan pengembangan wisata di Danau Batur yang ada di wilayah Desa Abangsongan belum dikembangkan secara optimal. Sampai saat ini, wisatawan yang berkunjung ke Danau Batur biasanya hanya di wilayah Danau Batur yang ada di Desa Penelokan saja. Oleh karena itu, perlu adanya pengembangan sarana dan prasarana guna menunjang kebutuhan wisatawan saat berkunjung ke kawasan Danau Batur yang ada di Desa Abangsongan.

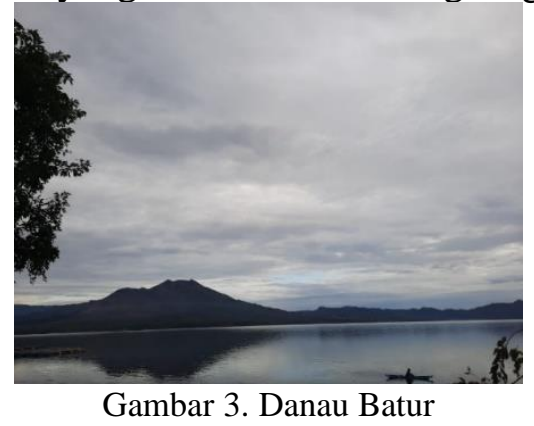

Selain dua daya tarik wisata yang dijelaskan oleh penulis di atas ternyata di Desa Abangsongan juga terdapat potensi wisata lainnya seperti peternakan madu hutan, kuliner mujair nyat-nyat sebagai makanan khas dan kegiatan budaya yang bisa dijadikan untuk atraksi 
tambahan dalam usaha pengembangan wisata disana. Hal ini dapat juga berarti bahwa pengelolaan sarana dan prasarana wisata yang ada di Desa Abangsongan belum optimal. Kreativitas dan inovasi masih dibutuhkan agar mampu mendukung potensi daya tarik utama wisata alam yang ada di Desa Abangsongan yakni keindahan lansekap geografis serta indahnya pemandangan yang tersaji di sana.

\subsection{Strategi Pengembangan Daya Tarik Wisata Alam}

Penentuan pengelompokkan faktor kekuatan, kelemahan, peluang dan ancaman pada penelitian ini berdasarkan pada hasil wawancara dengan pemuka desa, pengelola jasa usaha wisata serta masyarakat lokal disana mengenai arah pengembangan potensi wisata alam di Desa Abangsongan terutama di Gunung Abang dan Danau Batur yang sesuai dengan visi Desa Abangsongan sendiri yaitu " Terwujudnya masyarakat Desa Abangsongan yang SANTI ( sejahtera, aman, nyaman, tertib, dan indah ) dengan tetap mensejajarkan kemampuan diri dengan lingkungan sekitarnya bersama masyarakat Desa Abangsongan yang berlandaskan Tri Hita Karana". Dalam hal ini, dapat kita lihat bahwa visi dari Desa Abangsongan itu bahwa pengembangan potensi wisata alam diharuskan mengikuti filosofi Tri Hita Karana. Filosofi Tri Hita Karana merupaakn tiga elemen yang mampu menciptakan kebahagiaan, harmoni dan keseimbangan dalam kehidupan. Ketiga elemen tersebut adalah hubungan anatara manusia dengan Tuhan (Parahyangan), manusia dengan sesama manusia (Pawongan) dan manusia dengan alam dan lingkungannya (Palemahan). Jadi, strategi yang yang dirumuskan pun harus selaras dengan visi dari Desa Abangsongan tersebut.

\subsection{Analisis SWOT Pengembangan Potensi Wisata Alam Di Desa Abangsongan Kintamani}

Analisis SWOT merupakan identifikasi berbagai faktor secara sistematis untuk merumuskan suatu strategi perusahaan, (Rangkuti 2006:19). SWOT merupakan singkatan dari lingkungan internal strengths (kekuatan) dan weaknesses (kelemahan) serta lingkungan eksternal opportunities (peluang) dan threats (ancaman) yang dihadapi di dunia bisnis. Analisis didasarkan pada logika yang dapat memaksimalkan kekuatan (strengths) dan peluang (opportunities), namun secara bersamaan dapat meminimalkan kelemahan (weaknesses) dan ancaman (threats). Dalam penyusunan strategi pengembangan potensi wisata alam di Desa Abangsongan perlu dilakukan analisis SWOT terlebih dahulu untuk mengidentifikasi faktor kekuatan, kelemahan, peluang dan ancaman (Cornelis,. Fanggidae,A., \& Timuneno,2019). Dari hasil wawancara dengan para pemangku kepentingan serta hasil observasi langsung di lapangan maka diperoleh hasil mengenai faktor pendukung dan penghambat pengembangan potensi wisata alam di Desa Abangsongan antara lain :

\section{a. Kekuatan (Strength)}

1. Banyak memiliki potensi wisata alam yang menarik seperti Gunung Abang, Danau Batur dan hutan wisata.

2. Suasana alam yang masih terjaga keasliannya.

3. Letak potensi wisata yang strategis yaitu berada di jalur wisata kawasan Kintamani.

4. Kondisi geografis dan lansekap yang indah dengan iklim yang sejuk.

b. Kelemahan (Weakness)

1. Masih belum adanya dana dan anggaran untuk pengembangan potensi wisata alam di sana.

2. Faktor keterbatasan SDM professional dan terampil.

3. Belum adanya jalinan kerjasama kemitraan dengan mitra bisnis industri

4. Kurangnya prasarana dan sarana yang memadai untuk mendukung kegiatan wisata.

5. Kurangnya informasi dan promosi dari pemerintah 


\section{c. Peluang (Opportunity)}

1. Terletak di jalur obyek wisata lainnya di Kecamatan Kintamani sehingga bisa dijadikan peluang untuk dimasukkan dalam paket wisata di Kintamani.

2. Adanya dukungan dari semua pihak yang ada di Desa Abangsongan mulai dari pemuka desa, pemuda, pemilik usaha wisata dalam pengembangan potensi wisata alam di sana.

3. Para investor masih bisa ikut masuk dan berpartisipasi dalam pengembangan potensi wisata alam yang ada di sana maupun mengeksplorasi potensi wisata baru.

4. Minat wisatawan terhadap wisata alam dan wisata minat khusus masih tinggi

\section{d. Ancaman (Threat)}

1. Bencana alam seperti erosi dan tanah longsor`

2. Sampah dan vandalism

3. Konflik pemanfaatan ruang

4. Jarak yang berdekatan dengan obyek wisata lainnya memiliki resiko wisatawan lebih memilih berkunjung ke destinasi wisata lainnya.

Di bawah ini, penulis menuliskan matriks SWOT dari hasil yang didapatkan di lapangan. Matriks di bawah ini menghasilkan empat kemungkinan alternatif strategi yaitu Strategi StrengthOpportunities (Strategi S-O), Strategi StrengthThreats (Strategi S-W), Strategi WeaknessOpportunities (Strategi W-O), dan Strategi WeaknessThreats (Strategi W-T).

Tabel 1. Matriks SWOT

\begin{tabular}{|c|c|c|}
\hline & $\begin{array}{c}\text { KEKUATAN } \\
(\text { KTRENGTH- } \\
\text { S })\end{array}$ & $\begin{array}{c}\text { KELEMAHAN } \\
\text { (WEAKNESS- } \\
\text { W })\end{array}$ \\
\hline $\begin{array}{c}\text { PELUANG } \\
(\text { OPPORTUNITY- } \\
\text { O })\end{array}$ & $\begin{array}{c}\text { STRATEGI } \\
\text { SO }\end{array}$ & $\begin{array}{c}\text { STRATEGI } \\
\text { WO }\end{array}$ \\
\hline ANCAMAN & STRATEGI & STRATEGI \\
$($ THREATS-T $)$ & ST & \\
& & \\
\hline
\end{tabular}

\section{Strategi SO (Strength Opportunity)}

Strategi ini menggunakan kekuatan yang dimiliki sebagai peluang dalam pengembangan wisata alam di Desa Abangsongan. Strategi SO ini di antaranya Melakukan promosi dan publikasi salah satunya dengan pembuatan paket wisata alam dan wisata minat khusus Kintamani dengan memasukkan potensi wisata alam di Desa Abangsongan seperti Gunung Abang. Membangun jalur trekking, sarana outbond, guna mengoptimalkan potensi wisata alam yang ada.

\section{Strategi ST ( Strength Threats)}

Strategi ini menggunakan kekuatan yang dimiliki untuk mengatasi ancaman dalam pengembangan potensi wisata alam di Desa Abangsongan. Strategi ST ini yaitu dengan Melakukan penyuluhan dan pelatihan mengenai konservasi lingkungan dan kawasan bagi masyarakat lokal dan para pelaku usaha dan jasa wisata di kawasan terkait. Melakukan koordinasi dengan pihak terkait potensi wisata alam mengenai perlindungan dan pengawasan di kawasan wisata terkait. Melakukan evaluasi dan monitoring secara berkala dengan pihak aparat desa, pelaku jasa wisata dan masyarakat lokal mengenai perkembangan wisata di sana. 


\section{Strategi WO (Weakness Opportunity)}

Strategi ini merupakan strategi yang meminimalkan kelemahan untuk memanfaatkan peluang yang ada dalam pengembangan potensi wisata alam di Desa Abangsongan.Strategi WO ini adalah dengan melakukan kolaborasi atau kerja sama dengan para investor untuk bersama-sama mengembangkan dan mengelola potensi wisata yang ada di Desa Abangsongan. Kedua dengan menyusun rencana pengelolaan dan memantapkan pembangunan kawasan wisata agar bisa mengoptimalkan potensi wisata yang ada.

\section{Strategi WT (Weakness Threats)}

Strategi ini merupakan strategi yang meminimalkan kelemahan dan mengatasi ancaman yang ada dalam pengembangan potensi wisata alam di Desa Abangsongan. Strategi WT ini yaitu melakukan pemberdayaan bagi masyarakat lokal di Desa Abangsongan. Strategi selanjutnya melakukan pelatihan dalam bidang kepariwisataan seperti pelatihan tour guiding, pengelolaan homestay, pelatihan culinary.

\section{Kesimpulan}

Berdasarkan uraian pada hasil analisis dan pembahasan yang telah dilakukan dalam penelitian ini maka dapat diambil kesimpulan yaitu kawasan daya tarik wisata alam di Desa Abangsongan masih bisa dikembangkan dengan memeprhatikan faktor kekuatan, kelemahan, peluang dan ancaman yang ada. Selain itu, pemerintah desa serta pengelola bisa juga menjadikan faktor kekuatan dan peluang untuk upaya pengembangan pariwisata di sana. Perumusan strategi pengembangan potensi wisata alam di Desa Abangsongan menghasilkan 9 strategi yaitu

1. Promosi dan publikasi melalui pembuatan paket wisata.

2. Pembangunan jalur trekking dan sarana outbond

3. Pelatihan dan penyuluhan konservasi lingkungan

4. Koordinasi perlindungan kawasan wisata

5. Evaluasi dan monitoring secara berkala mengenai dampak pariwisata.

6. Kolaborasi dan kerja sama dengan investor mengenai pengembangan dan pengelolaan potensi wisata alam yang ada.

7. Pemberdayaan masyarakat sekitar kawasan wisata di Desa Abangsongan khusunya sekitar Danau Batur dan Gunung Abang.

8. Pembuatan rencana pengelolaan dan pemantapan kawasan wisata di Desa Abangsongan.

9. Pelatihan dalam bidang kepariwisataan seperti pelatihan tour guiding, pengelolaan homestay dan pelatihan culinary.

\section{Saran}

Diperlukan adanya penelitian lebih lanjut mengenai pengembangan wisata lebih khusus dan spesifik untuk mengembangkan potensi wisata alam di Desa Abangsongan agar lebih dikenal oleh wisatawan.

\section{Ucapan Terimakasih}

Terimakasih kami sampaikan kepada Pusat Penelitian dan Pengabdian kepada Masyarakat Politeknik Negeri Bali atas support dan dukungan yang diberikan sehingga penelitian dan pengabdian di Desa Abangsongan ini bisa terlaksana. 


\section{Daftar Pustaka}

Bryson, John. M, 1999, Perencanaan Strategis bagi Organisasi Sosial, Pustaka Pelajar, Jakarta. Bungin, M. Burhan. 2008. Penelitian Kualitatif. Jakarta: Kencana Prenada Group.

Cooper (ed), 1998, Tourism Planning: Basics Concept Cases. Singapore, Prentice Hall.

Cornelis, C. A. E., Fanggidae, A. H. J., \& Timuneno, T. (2019). Strategi Pengembangan Objek Wisata Alam Gunung Fatuleu. Journal of Management (SME's), 8(1), 117-132.

Hermawan, H. (2017). PENGARUH DAYA TARIK WISATA, KESELAMATAN, DAN SARANA WISATA TERHADAP KEPUASAN SERTA DAMPAKNYA TERHADAP LOYALITAS WISATAWAN : Studi Community Based Tourism di Gunung Api Purba Nglanggeran. Wahana Informasi Pariwisata: MEDIA WISATA, 15(1). https://doi.org/10.31219/osf.io/89hqd

Ismayanti, 2010, Pengantar Pariwisata. Jakarta, PT Gramedia Widisarana Indonesia.

Itamar, H., Alam, A. S., \& Rahmatulah. (2014). Strategi Pengembangan Pariwisata di Kabupaten Tana Toraja Hugo. Jurnal Ilmu Pemerintahan, 7(2), 91-108. http://journal.unhas.ac.id/index.php/government/article/view/1248/pdf

Mahfud, T., Mulyani, Y., Indartono, S., \& Setyawati,R. 2018. Community-based tourism development: Foodies community strategy to culinary tourism development in Balikpapan-Indonesia. Journal of Tourism and Management Research, 3(2), 274-289.

Pearce, D, 1981, Tourist Development. University of Cantenbury, New Zealand.

Pendit, Nyoman.S, 2002. Ilmu Pariwisata: Sebuah Pengantar Edisi Revisi, Jakarta, PT. Pradnya Paramita.

Peraturan Bupati (Perbup) Bangli Nomor 4 Tahun 2018 tentang Perbuahan Ketiga atas Perbup Bangli Nomor 16 Tahun 2014 tentang Desa Wisata.

Rangkuti, Freddy. 2006. Analisis SWOT: Teknik Memmbedah Kasus Bisnis.Jakarta: PT GramediaPustaka Utama.

Soejono, dan Abdurrahman, 1999, Metode Penelitian, Jakarta, PT RIENEKA CIPTA Undang-Undang No. 9 Tahun 2009 Tentang Kepariwisataan.

Yoeti, Oka. A, 2008, Perencanaan dan Pengembangan Pariwisata, Pradnya Paramita, Jakarta. 